University of Texas at El Paso

ScholarWorks@UTEP

7-2019

\title{
Why Pink Noise Is Best for Enhancing Sleep and Memory: System- Based Explanation
}

\author{
Griselda Acosta \\ The University of Texas at El Paso, gvacosta@miners.utep.edu \\ Eric Smith \\ The University of Texas at El Paso, esmith2@utep.edu \\ Vladik Kreinovich \\ The University of Texas at El Paso, vladik@utep.edu
}

Follow this and additional works at: https://scholarworks.utep.edu/cs_techrep

Part of the Applied Mathematics Commons

Comments:

Technical Report: UTEP-CS-19-63

Published in Applied Mathematical Sciences, 2019, Vol. 13, No. 14, pp. 677-680.

\section{Recommended Citation}

Acosta, Griselda; Smith, Eric; and Kreinovich, Vladik, "Why Pink Noise Is Best for Enhancing Sleep and Memory: System-Based Explanation" (2019). Departmental Technical Reports (CS). 1340.

https://scholarworks.utep.edu/cs_techrep/1340

This Article is brought to you for free and open access by the Computer Science at ScholarWorks@UTEP. It has been accepted for inclusion in Departmental Technical Reports (CS) by an authorized administrator of ScholarWorks@UTEP.For more information, please contact Iweber@utep.edu. 


\title{
Why Pink Noise Is Best for Enhancing Sleep and Memory: System-Based Explanation
}

\author{
Griselda Acosta ${ }^{1}$, Eric Smith ${ }^{2}$, and Vladik Kreinovich ${ }^{3}$ \\ ${ }^{1}$ Department of Electrical and Computer Engineering \\ ${ }^{2}$ Department of Industrial, Manufacturing, and \\ Systems Engineering \\ ${ }^{3}$ Department of Computer Science \\ University of Texas at El Paso \\ $500 \mathrm{~W}$. University \\ El Paso, TX 79968, USA \\ gvacosta@miners.utep.edu, esmith2@utep.edu,vladik@utep.edu
}

\begin{abstract}
Several researchers found out that acoustic stimulation during sleep enhances sleep and enhances memory. An interesting - and somewhat mysterious - part of this phenomenon is that out of all possible types of noise, the pink noise leads to the most efficient stimulation. In this paper, we use general system-based ideas to explain why in this phenomenon, pink noise works best.
\end{abstract}

\section{Formulation of the Problem}

Acoustic stimulation helps sleep and memory: a brief description of the observed phenomenon. Several researchers found out that acoustic stimulation during sleep help patients to sleep better and enhanced their memory; see, e.g., $[4,5,6,8]$.

Qualitative explanation of the phenomenon. While the level of enhancement was much higher than most researchers expected, the very fact that exercising some organ is good should be expected: it helps to exercise muscles, it helps to exercise brain activities, it helps to exercise visual activities, etc.

It is also understandable that a noise helps better than a signal emitted at a single frequency: just like exercising different muscles is better for a person's overall health than focusing on a single group of muscles, just like practicing different types of mental activities is better for a person's mental abilities than repeatedly performing tasks of the same type, it is reasonable to expect that processing components of different frequencies will work better than processing only one frequency. 
Pink noise: why? The best stimulation results were obtained when the researchers applied pink noise, i.e., the noise in which the power spectral density $S(f)$ (i.e., energy per unit frequency) is inverse proportional to the frequency itself: $S(f)=\frac{c}{f}$ for some constant $c$.

From the biological viewpoint, this may not be that surprising, since the pink noise is the most common signal in biological systems; see, e.g., [7] (see also [2] and references therein). In particular, pink noise is a good description of signals corresponding to mental activities; see, e.g., [?]. Pink noise is also ubiquitous in nature in general: e.g., in describes the statistical structure of many natural images; see, e.g., [1].

However, from the scientific viewpoint, the efficiency of pink noise is still somewhat a mystery, since it is not clear why the use of the most biological signal would lead to a better enhancement than any other possible signals.

What we do in this paper. In this paper, we provide a system-based explanation of why pink noise is the most efficient one.

\section{Our Explanation}

Main idea. As we have mentioned earlier, the best results are usually achieved when different organs, different parts of the organs are all involved. With respect to frequencies, this means that the biological acoustic sensors corresponding to all the frequencies should be involved.

Of course, if on one of the frequencies, we have a very weak signal, this means that the sensor corresponding to this frequency is practically not exercised ar all. So, to make sure that the exercise leads to the largest possible effect, it is reasonable to require that each of these sensors is exercised similarly, i.e., in precise terms, that the energy of the part of the signal affecting each sensor will be the same for all sensors.

To describe this idea in precise terms, we need to recall which part of the signal is affecting each of these sensors.

Acoustic perception: a particular case of the general Weber's law. In general, our perception - be it visual or acoustic or any other - follows the Weber's law, according to which, for each perceived quantity $x$, the just noticeable difference $\Delta_{x}$ is proportional to the actual value of this quantity, i.e., $\Delta_{x}=\delta \cdot x$ for some $\delta>0$; see, e.g., [3].

In particular, for the frequency, this means that for each frequency $f$, the just noticeable difference in frequency $\Delta_{f}(f)$ should be proportional to the frequency itself, i.e., we should have $\Delta_{f}(f)=\delta \cdot f$, for some value $\delta>0$. In other words, each biological acoustic sensor corresponding to a certain frequency $f$ actually takes in all the frequencies from $f$ to $f+\Delta_{f}(f)=f+\delta \cdot f$.

What will happen is we have a signal with power spectral density $S(f)$ ? By definition, the power spectral density is the energy per unit frequency. Thus, to get the overall energy $E(f)$ affecting this sensor, we need to multiply the 
power spectral density $S(f)$ by the width $\Delta_{f}(f)$ of the corresponding frequency interval $\left[f, f+\Delta_{f}(f)\right]$. As a result, we get the value

$$
E(f)=S(f) \cdot \Delta_{f}(f)=S(f) \cdot \delta \cdot f .
$$

As we have mentioned, the best effect is expected when each sensor gets the exact same amount of energy, i.e., when $E(f)=$ const. For the above expression $E(f)=S(f) \cdot \delta \cdot f$, the requirement $E(f)=$ const means that, to achieve the best effect, we should use the power spectral density $S(f)=\frac{\text { const }}{\delta \cdot f}$. This is exactly the pink noise, with $c=\frac{\text { const }}{\delta}$. Thus, we have indeed explained why, out of all possible types of acoustic noises, the pink noise leads to the most efficient stimulation of sleep and memory.

\section{Acknowledgments}

This work was supported in part by the National Science Foundation via grants 1623190 (A Model of Change for Preparing a New Generation for Professional Practice in Computer Science) and HRD-1242122 (Cyber-ShARE Center of Excellence).

\section{References}

[1] D. J. Field, "Relations between the statistics of human images and the response properties of cortical cells", Journal of the Optical Society of America, Series A, 1987, Vol. 4, No. 12, pp. 2379-2394.

[2] B. D. Josephson, "A trans-human source of musics?", In: P. Pylkkännen and P. Pylkkö (eds.), New Directions in Cognitive Science, Finnish Artifical Intelligence Society, Helsinki, Finland, 1995, pp. 280-285.

[3] E. R. Kandel, J. H. Schwartz, T. M. Jessell, S. A. Siegelbaum, and A. J. Hudspeth (eds.), Principles of Neural Science, McGraw Hill, New York, 2013.

[4] H. V. Ngo, T. Martinetz, J. Born, and M. Mölle, "Audiroty closed-loop stimulation of the sleep slow oscillation enhances memory", Neuron, 2013, Vol. 78 , pp. 545-553.

[5] J. L. Ong, J. C. Lo, N. I. Y. N. Chee, G. Santostasi, K. A. Paller, P. C. Zee, et al., "Effects of phase-locked acoustic stimulation during a nap on EEG spectra and declarative memory consolidation", Sleep Medicine, 2016, Vol. 20, pp. 88-97.

[6] N. A. Papalambros, G. Santostasi, R. G. Malkari, R. Braun, S. Weintraub, K. A. Paller, and P. C. Zee, "Acoustic enhancement of sleep slow oscillations and concomitant memory enhancement in older adults", Frontiers in Human Neuroscience, 2017, Vol. 11, Article 109. 
[7] P. Szendro, "Pink-noise behavior of biosystems", European Biophysics Journal, 2001, Vol. 30, No. 3, pp. 227-231.

[8] G. Tononi, B. A. Riedner, B. K. Hulse, F. Ferrarelli, and S. Sarasso, "Enhancing sleep slow waves with natural stimuli", Medicamundi, 2010, Vol. 54, pp. $82-88$.

[9] G. C. Van Orden, J. G. Holden, and M. T. Turvey, "Self-organization of cognitive performance", Journal of Experimental Psychology: General, 2003, Vol. 132, No. 3, pp. 331-350. 